УДК 378.02:37.016

DOI 10.17223/18137083/60/21

\title{
Ван Синхуа
}

Томский государственный педагогический университет

\section{Русские и китайские молодежные жаргонизмы как проявление национальной лингвокультуры и объект научного исследования}

\footnotetext{
Статья посвящена рассмотрению функционально-прагматических особенностей жаргонизмов, фигурирующих в речи русских и китайских молодых людей, в сопоставительном аспекте с учетом роли экстралингвистических факторов. Черты сходства между китайскими и русскими жаргонизмами обусловливаются ориентацией культур обеих стран на западную модель. Единицы молодежного жаргона в первую очередь определяются в качестве лингвокультурологических, опосредующих внутри- и межкультурную коммуникацию. Обосновывается также возможность использования русских молодежных жаргонных слов и выражений в практике обучения русскому языку как иностранному носителей китайского языка.

Ключевые слова: жаргон, молодежный жаргон, жаргонизмы, лингвокультура, межкультурная коммуникация.
}

Поворот науки к личностным аспектам изучения и функционирования языка, к его рассмотрению в широком социолингвистическом и межкультурном контексте предопределил возникновение интереса к исследованию нелитературных стратов языковой системы, включая жаргонизмы. Понимание молодежного языка как особого явления культуры, значимость которого очевидна для многих сфер социальной коммуникации, во многом расширяет проблемное поле исследования речи молодежи (Е. Г. Борисова, М. А. Грачев, Е. Н. Гуц, В. С. Елистратов, О. П. Ермакова, Е. А. Земская, Л. П. Крысин, В. М. Мокиенко, Г. П. Нещименко, Т. Г. Никитина, Ю. А. Панова, Р. И. Розина, Л. И. Скворцов, О. Б. Трубина, В. В. Химик и др.). Актуальность изучения жаргонных единиц обосновывается также тем, что на протяжении долгого времени было вообще не принято заниматься исследованием жаргона, в том числе молодежного, как языкового явления: «В середине XX столетия на молодежный жаргон смотрели как на “испорченный” язык, рас-

Ван Синхуа - старший преподаватель кафедры теории языка и методики обучения русскому языку Томского государственного педагогического университета (ул. К. Ильмера, 15/1, корп. 8, Томск, 634057, Россия; paveltgpu@yandex.ru)

ISSN 1813-7083. Сибирский филологический журнал. 2017. № 3

(C) Ван Синхуа, 2017 
сматривали как объективный, но нежелательный для общества феномен» [Бахтина, 2011, с. 4].

«В состав молодежного жаргона входят единицы, активно употребляемые в речи молодыми людьми в возрасте 18-30 лет. Существование молодежного жаргона как особого социокультурного феномена во многом определяется потребностью в “своих”, корпоративных, более выразительных эмоционально-экспрессивных вторичных наименованиях, которые подчеркивают возрастное и психологическое единство молодежи, ее противопоставленность, негативное или критическое отношение как к официальной культуре, так и к общепринятой форме общения» [Ван Синхуа, Курьянович, 2016а, с. 9].

В последнее время все чаще появляются работы, посвященные анализу жаргонизмов как лингвокультурологических единиц, результативно функционирующих на уровнях внутри- и межкультурной коммуникации (Т. А. Кудинова, Н. С. Иванова и др.).

Целью данной статьи является сопоставительное изучение жаргонизмов русского и китайского языков в аспекте реализации ими своих функциональнопрагматических свойств в разнообразных сферах социального взаимодействия, а также рассмотрение данных единиц в качестве объекта научных разысканий в разных областях фундаментальной и практикоориентированной лингвистики.

Китайские русисты - специалисты в области преподавания русского языка как иностранного - уже на протяжении долгого времени обращают пристальное внимание на интенсивное распространение жаргонизмов в современной русской речи и оценивают русский молодежный жаргон как особое и весомое явление, присутствующее в языке и интенсивно развивающееся. Речь молодежи выступает как знак и символ русской молодежной культуры, является мощным фактором, воздействующим на развитие языка. С 80-х гг. ХХ в. эта проблема активно анализируется в монографиях, научных статьях, учебных пособиях китайских специалистов.

Этапы исследования русского молодежного сленга в Китае можно разделить три периода ${ }^{1}$.

Первый период - период теоретического формирования (с середины 80-х до начала 90-х гг. ХХ в.). Появление в 1985 г. первого специализированного словаря на русско-китайском языке «Запись русского воровского арго» профессора Сунь Мэнбяо ${ }^{2}$ дало толчок изучению русского сленга в Китае. Планомерно рос интерес китайских русистов к языковому феномену сленга в его соотношении с терминами «арго» и «жаргон» (см., например, работы Чжан Баошан «Особенности тайных языков молодежи» $(1987)^{3}$, Дин Синь «О русском сленге» $\left.(1988)^{4}\right)$.

Второй период - период интенсивного развития (с начала 90-х гг. ХХ в. до начала XXI в.). Например, в 1992 г. в Вестнике Шэньянского университета была опубликована статья «Описание диалекта, сленга и жаргона в русском языке» 5 , авторы которой анализировали специфику соотношения ключевых понятий. Учеными был сделан вывод о том, что разные слои общества общаются на разных подъязыках (жаргоне, сленге) в соответствии с особенностями возраста, общественного статуса, уровня образования и т. п. В 2000 г. в учебно-методическом журнале «Русский язык в Китае» была опубликована статья «Популярный рус-

\footnotetext{
${ }^{1}$ Подробнее см.: 俄语青年俚语的文化阐释 [Культурный анализ русского молодежного сленга]. URL: https://goo.gl/kZjTUv (дата обращения 29.08.2016).

2 俄语盗贼黑话辑录. URL: http://max.book118.com/html/2015/0921/25847643.shtm (дата обращения 27.08.2017).

3 俄语青年隐语的特点. URL: https://goo.gl/UmcmXt (дата обращения 27.08.2017).

4 试论俄语俚语. URL: https://goo.gl/M2jkG7(дата обращения 27.08.2017).

5 俄语方言、俚语及行话浅论. URL: http://goo.gl/1VYY3q (дата обращения 02.09.2016).
} 
ский молодежный жаргон», посвященная анализу проблемы популяризации жаргонизмов в молодежной речи и отражения этого процесса в молодежных журналах и СМИ ${ }^{6}$. В конце $\mathrm{XX}$ в. появился ряд научных трудов, посвященных вопросу изучения истории и системного развития русского молодежного жаргона. В их

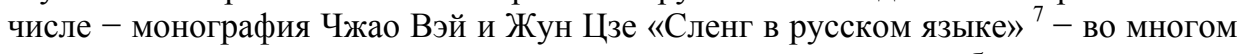
новаторское исследование, в котором всестороннее и подробно описываются функционально-прагматические особенности сленга XX в.

Третий период - период многоаспектного исследования: социального, этнического, лингвокультурологического и пр. (с начала XXI в. и до настоящего времени). В этот период китайскими русистами активно защищаются магистерские диссертации, касающиеся разноаспектного освещения жаргона и жаргонизмов. Так, в научном исследовании Су Жина «Исследование русской молодежной субкультуры на материале русского сленга» (магистерская диссертация защищена в Университете Внутренней Монголии в 2007 г.) освещаются вопросы взаимосвязи молодежной субкультуры и молодежного сленга. В магистерской диссертации Чэн Чэнь «Сопоставительное исследование молодежных сленгов в китайском и русском языках», защищенной в 2011 г. в Шаньдунском университете, посредством привлечения сопоставительного анализа выявлены общие и различные черты, характерные для словообразования и стилистической окраски китайских и русских жаргонных единиц. Появление черт сходства и отличия обусловлено, по мнению автора, совокупным действием экстралингвистических и собственно лингвистических факторов. В мае 2015 г. в Институте иностранных языков педагогического университета Центрального Китая (г. Ухань) была защищена магистерская диссертация Хань Сюели на тему «Лингвокультурологический анализ современного русского молодежного жаргона». Автор рассматривает проблему изучения современного русского молодежного жаргона в следующих ключевых аспектах: анализирует его место и роль в системе национального языка, размышляет об источниках пополнения лексического состава молодежного жаргона, словообразовательных процессах в лексике современного русского молодежного жаргона, ставит вопрос об изучении молодежного жаргона с позиции лингвокультуры ${ }^{8}$. О повышенном интересе китайских лингвистов к русскому молодежному жаргону свидетельствует также факт регулярного издания в Китае специализированных словарей и справочников. Приведем два наиболее известных: «Новый русско-китайский словарь сленга» [Дин Синь, 2008], «Новейший русскокитайский словарь популярных слов» [Сюй Юпин, 2006].

В последние годы наблюдается устойчивая тенденция исследования единиц русского и китайского молодежного жаргона в их сопоставлении с позиций рассмотрения специфики функционирования и проявления прагматических и лингвокультурологических свойств. Например, интересна в этом отношении работа Сюн Вэй «Культурный анализ русского молодежного сленга в аспекте китайской лигвокультуры» 9 .

Чрезвычайно актуальным является изучение русского молодежного жаргона как собственно языкового и шире - лингвокультурологического феномена не только в рамках фундаментального подхода, но и с позиций лингводидактики и методики обучения русского языка как иностранного (см., например, об этом: [Ван Синхуа и др., 2015]). Русский молодежный жаргон и его единицы (конечно,

\footnotetext{
${ }^{6}$ 近年流行的俄罗斯青年俚语. URL: https://goo.gl/gZ3JjW (дата обращения 27.08.2017).

7 赵为, 荣洁 《俄语俚语研究. URL: http://book.kongfz.com/16337/259272248 (дата обращения 27.08.2017).

${ }^{8}$ См. информацию о перечисленных магистерских диссертациях: 俄罗斯青年俚语论文. URL: https://goo.gl/w5foLY (дата обращения 29.08.2016).

${ }^{9}$ Там же.
} 
при соблюдении условия соответствия коммуникативным нормам) стали составной частью дидактической базы в освоении русского языка в Китае и активно используются на занятиях по лексикологии, разговорной практике, аудированию, лингвострановедению и пр. Китайские студенты проявляют интерес к изучению русского молодежного жаргона как «модного» языка, маркера принадлежности к корпоративной культуре. С этой целью китайскими преподавателями русского языка широко задействуется интернет: создаются специализированные сайты, пользователи которых имеют возможность обмениваться информацией и делиться опытом из практики обучения русскому языку. Например, на портале «俄语之 家 Russian Club» («Клуб русского языка») в рубрике 战斗名族的语言:地地道道的 俄语青年俚语、行话让你越来越时髦 («Русский язык, язык мужественной нации: изучение чистого русского молодежного сленга сделает твою речь модной») можно познакомиться с подборкой русских молодежных жаргонизмов, сопровожденных китайским переводом ${ }^{10}$. Приведем примеры:

(1) «Тича» от «teacher» - учитель 老师. Например: Тича сегодня придет на урок или нет? 今天老师来上课么?

(2) «Лафа, катать вату» - бездельничать 无所事事. Например: Tы опять катаешь вату? Иди, работай! 你又无所事事, 去工作!

(3) «Стыбрил, спер» - украл 作弊. Например: Смотри, он стыбрил у нее ручку. 看! 她又作弊了.

(4) «Шпора»- ипаргалка 打小抄. Например: Я вчера всю ночь эти ипоры пиcaл. 我昨天整夜都在写这些小抄.

(5) «Тема»- отлично, мне нравится 我很喜欢. Например: O-о-о, это тема, тогда завтра в 3 часа встречаемся!!! 明天三点见面, 这个我喜欢.

(6) «Бро» от «brother» (брат, друг) 哥哥 (弟弟), 朋友. Например: Бро, как $m b l, \kappa a \kappa$ дела? 朋友你最近怎么样?

(7) «3ырить»-смотреть 看. Например: Что она так зырит на меня? 为什么 她这样看着我?

(8) «Стучать»- жаловаться 打小报告. Например: Он опять настучал преподавателю. 他又向老师打小报告.

(9) «Ништяк» - хорошо, пойдет, неплохо 还行. Например: - Как вы вчера отдохнули? - Ништяк, было очень весело. 昨天您休息的怎么样? 还行, 挺好的.

(10) «Труба, крышка»- наказание за проделанные проступки 教训. Например: Все, нам труба, родители узнали об этом. 父母知道的话会教训我们的.

(11) «Влом»- лень 懒. Например: Мне влом туда идти, сходи сам. 我懒得去 那，你自己去吧.

(12) «Облом»-когда действительное не совпало с ожиданием 失望. Например: Облом, сегодня не получится уйти с работь пораньше, директор еще здесь. 太失望了, 今天不能早点下班, 经理还在呢.

(13) «Тормоз, тупак» - глупьй 笨蛋. Например: Ну, ты и тормоз!!! Опять неправильно написал. 你这个笨蛋! 又写错了.

(14) «Чувак, чувачок»- парень, парнишка 男孩儿. Например: Чувак, ты что такой грустный, не переживай, всё будет хорошо! 男孩儿, 你为什么这么沮丧 啊, 别担心, 一切都会好的.

Проникновению русских молодежных жаргонизмов в речевую повседневную коммуникацию китайцев способствует регулярная демонстрация на китайском

10 俄语之家地地道道的俄语青年俚语、行话让你越来越时髦. 17-02-2016 23:27. URL: http://www.wtoutiao.com/p/12frchj.html (дата обращения 28.08.2016). 
сайте «腾讯» («Тэнсюнь») роликов, содержащих видеозаписи различных русских молодежных шоу и телесериалов («Камеди Вумен», «Камеди Батл», «Физрук», «Кухня» и пр.) ${ }^{11}$.

Молодежь любой страны - это наиболее «революционный» в плане создания и использования в речи новых единиц пласт общества. Именно молодые люди всегда активно и инициативно реагируют на изменения в окружающей их жизни. В китайском языке, особенно в последнее десятилетие, появилось много новых лексических единиц, называющих реалии современного Китая и отражающих большие изменения во всех сферах человеческой деятельности в стране. Новое поколение молодых людей в Китае (так называемые 八零 后, 九零 后, т. е. рожденные в 80 -е и 90-е гг. ХХ в.) застало период сближения китайской и западной культур. Некоторые представители этого поколения даже много лет жили на Западе и росли под сильным влиянием западной культуры. В отличие от старшего поколения, выросшего в дореформенный период (до 1978 г.), у выросших в 80-е (八零 后) и 90-е гг. (九零 后) XX в. формируется особая молодежная субкультура, включающая определенную систему ценностей, норм поведения и, конечно, свой подъязык. «Молодежная субкультура является особым социокультурным феноменом и характеризуется такими элементами, как определенные ценности и ценностные ориентации, специфические нормы и образцы поведения участников субкультурной группы, собственная статусная структура, источники информации и каналы коммуникации, определенный набор способов времяпрепровождения, вкусов и предпочтений, а также молодежная мода, жаргон и фольклор» [Целепидис, 2009, с. 31].

Сегодня модными можно считать такие частотные и характерные для речевой коммуникации внутри молодежного страта слова, как: 逗比 dòu b̌́ 'туповатый и славный человек'; 屌丝 diǎo sī 'никчемный, безголовый, бесперспективный человек'; 萌萌哒 méng méng dā 'очень симпатичный, милый'; 富二代 fù èr dài 'the second-generation rich; silver-spoon kids' (в русском молодежном жаргоне это обозначает «мажорик»); 暖男 nuăn nán 'положительный образ мужчины, который всегда приносит тепло сердцу; семьянин, который умеет готовить и стирать; красивая внешность, т. е. образ идеального мужа'; 小鲜肉 xiăo xiān ròu обычно: 'молодая и красивая звезда мужского пола (13-30 лет) в глазах своих фанатов (букв.: свежее мясо)'; 砖家 zhuān jiā 'фальшивый специалист, так называемый професcop'; 叫兽 jiàoshòu '(презрит.) так называемый профессор'; 尼玛 ní та̌ намек на самый распространенный китайский мат; 美届 тегi те́i 'красивая молодая девушка (букв.: красивые брови)'; 潜水 qián shuĭ 'спрятаться, чтобы другие не заметили, может быть, просто розыгрыш’; 神马 shén mă '(пренебр.) что?’; 拍砖 pāi zhuān 'возражать какому-то мнению в форуме или чате'; 青蛙 $q \bar{i} n g w \bar{a}$ 'парень с некрасивой внешностью'; 白菜 bái cài 'идиот’; 吐槽 tǔ cáo 'издевательство, сарказм'; 菜岛 cài niăo 'дурак, тупица, простофиля; новичок’; 粉丝 fěn sī 'фанат’; 颜 值 yán zhí оценка внешности; 狗带 gǒudài ‘иди, отстань, отвали!'; 出柜 chū guì 'заголубиться, признаться в нетрадиционной сексуальной ориентации (про мужской пол)'; 麻豆 má dòu 'поп-модель'; 葘丝 lěi sī 'лесбиянка' и пр. [Ван Синхуа, Курьянович, 2016б, с. 9-16].

Словник китайского молодежного жаргона всегда пополняется, идет в ногу со временем.

В 2011 г. ситуация вокруг использования жаргонизмов в повседневной коммуникации китайцев резко изменилась в связи с появлением WeChat (Вэйсинь, кuт.

11 腾讯视频. URL: http://v.qq.com/x/search/?q=камеди\&stag=txt.smart_resu (дата обращения 29.08.2016). 
微信, пиньинь: Wēixìn - досл. 'микросообщение') - мобильной коммуникационной системы для передачи текстовых и голосовых сообщений. По состоянию на 2013 г. в WeChat было зарегистрировано 300 млн пользователей; из них 70 млн за пределами Китая. WeChat поддерживает текстовые сообщения, передачу голосовых сообщений, рассылку сообщений множеству адресатов, возможность делиться фотографиями и видео. Есть возможность обмениваться контактами через Bluetooth, и, при желании, имеются разнообразные способы установления контактов со случайными людьми. Сервис интегрирован с социальными сетями, такими как Facebook и Tencent QQ. Есть возможность обрабатывать фотографии фильтрами и добавлять к ним надписи, также в WeChat доступен сервис машинного перевода ${ }^{12}$.

На сегодняшний день почти каждый молодой китаец зарегистрирован в «Вэйсинь». В этой системе китайцы знакомятся с новыми друзьями, делятся своим настроением, обмениваются информацией. В «Вэйсинь» формируется собственный стиль «вэйсиньского языка». В большинстве своем его составляющие оценочные, эмоционально-экспрессивные разговорные лексические единицы, просторечия, территориальные и социальные диалекты. Приведем примеры жаргонных единиц, функционирующих в пространстве межличностной повседневной коммуникации в социальной сети «Вэйсинь»: в 2013 г. в чате «Вэйсинь» появилась лексическая единица молодежного жаргона 绿茶婊lǜ chá biăo Grenn tea bitch 'проститутка или вообще девушка, которая создает себе девственно чистый имидж (букв.: зеленый чай + проститутка) ${ }^{13}$. На базе этого молодежного жаргонизма сформировалось несколько подобных лексических единиц, таких как: 奶茶 婊 năi chá biăo 'девушка с красивой внешностью, только гуляет с «высоким, богатым, красивым мажориком», любительница высококачественного перекуса (еда между основными приемами пищи), обожает приобретать разные подарки от любовника (букв.: проститутка + молочный кисель)'; 菊花婊 jú hua biăo 'приветливая, «всегда приятно пахнет от нее», но интриганка, стремится любой ценой добиться своей намеченной цели, даже своей плотью, но к своим друзьям хорошо относится (букв.: хризантема + проститутка)'; 咖啡婊 $k \bar{a}$ fe $i$ i biăo 'интеллигентная, тактичная, выглядит элитной, «всегда от нее вкусно пахнет», к ней все мужчины пытаются приблизиться, иметь интимные отношения, она не отказывается только от богатых ухажеров (букв.: кофе + проститутка)'; 普洱婊 Pǔ ěr biăo 'она с красивой внешностью, но «безбашенная», кроме учебы ничем не интересуется (букв.: чай «пуэр» + проститутка)'; 酱油婊 jiàng уóu biăo 'тусуется на разных пати, модная, шикарно одевается, «элитная шалава» (букв.: соевый соус + проститутка)'; 外围婊 wài wéi biăo 'называемая «поп-модель», маскируется в качестве модели или актрисы, а на самом деле путана, сопровождающая бизнесмена' ${ }^{14}$.

Сегодня молодежный жаргон как языковой феномен распространен в разных лингвокультурах, жаргонизация языка - наблюдающаяся тенденция развития языка не только в России, но и в мире в целом. Во многом этому способствовали такие исторические события в жизни России и Китая, как распад СССР и масштабная реализация политики реформ и открытости в Китае, обусловившие переход модели развития экономики обеих стран от плановой к рыночной. Изменения коснулись и духовной жизни социума, его культуры, в том числе молодежной.

Молодежь выступает в качестве особой социально-демографической, возрастной и психологической группы, которая является своеобразным маркером со-

\footnotetext{
${ }^{12}$ WeChat. URL: https://ru.wikipedia.org/wiki/WeChat (дата обращения 09.09.2016).

${ }^{13} \mathrm{https} / / /$ www.youtube.com/results?search_query=绿茶婊 (дата обращения: 09.09.2016).

14 天涯社区．URL: http://bbs.tianya.cn/post-free-3188134-1.shtml (дата обращения 01.09.2016).
} 
стояния общества. Молодежная субкультура воспринимается как автономное целостное образование внутри господствующей культуры, система ценностных установок и культурных традиций отдельной социальной группы, ведущей определенный образ жизни и имеющей определенный менталитет, обычаи, нормы, социальные институты; «совокупность специфических социально-психологических признаков (норм, ценностных ориентаций, стереотипов, вкусов, увлечений и т. п.), влияющих на стиль жизни и мышления определенных номинальных и реальных групп людей и позволяющих им осознать и утвердить себя в качестве “мы”, отличного от “они” (остальных представителей социума)» [Мудрик, 2004, c. 142]. Жаргон - это интереснейший языковой феномен и важнейший атрибут молодежной субкультуры. В живой, спонтанной речи молодежи наиболее популярной является жаргонная лексика, характеризующаяся ярким эмоциональнооценочным и экспрессивным характером. «Употребляя эти эмоционально-оценочные и экспрессивные слова и выражения, говорящий манифестирует либо имитирует свою принадлежность к определенной социальной группе и выражает свое отношение к окружающему с позиций этой социальной группы» [Химик, 2004, с. 23]. Молодежный жаргон выступает как своего рода пароль, молодые люди отождествляют себя с группой, употребляя общепринятый и общепризнанный язык молодежи. Употребление жаргонизмов демонстрирует и подтверждает принадлежность языковой личности к группе, показывает, что я - свой, наш.

На основании проанализированных источников по теме исследования, а также привлекая собственный опыт знакомства с единицами русского молодежного жаргона и их изучения, отметим их некоторые особенности. Обращает на себя внимание присутствие в жаргоне молодых русских людей большого количества лексем, свидетельствующих о влиянии, которое оказывает на русскую молодежь западная, в том числе американская культура. В западной социологии массовая культура рассматривается как коммерческая, «так как произведения искусства, религии, науки выступают в ней в качестве предметов потребления, способных при продаже приносить большую прибыль, если они учитывают вкусы и запросы массового зрителя, любителя музыки, читателя. И все это проникает сегодня в Россию, разрушая и без того слабую молодежную психику» ${ }^{15}$. Сегодня значительная часть русских молодых людей придерживается западной гедонистической философии. В их жизни рекреативные досуговые ориентации часто преобладают над познавательной деятельностью.

Приведем примеры зафиксированных в нашем карманном словаре жаргонных слов и выражений лексических единиц, принадлежащих к определенным тематическим группам. Тематическая группа «алкоголизм»: бухало, бухалово, бухло, бухляк, бухлянка, дринк, дринч, дринкало, кирок, синее, синева, синька, сулейка, султыга, косорыловка, пивчара, водяра, бортомуха и др.; группа «наркомания»: балда, вмазка, витамины, дрянь, дуреха, дурь, крапива, кайф, кашка, косяк, косячка, косячок, корм, лекарь, наркомат, наркота, отрава, топливо, торч, торчало, торчилка, торчок, трава, травка, химия, химка, шиза, шизуха, шира, ширево, шняга и др.; группа «криминал и нарушение правопорядка»: беспредел, блат, блатной, вешать, впарить, гопник, замочить, кинуть, кидало, мент, ментовка, ментяра, мусор, мочить, отмазать, отмазаться, отмазка, пахан, повязать, подставить, подставка, разборка, развести, развод, тьрить, тюряга и др. Примеры взяты из приложения-словника в работе М. Б. Бахтиной [2011].

Расшатывается традиционная, исторически сформировавшаяся система ценностей, формируются новые критерии отношения к окружающим людям (naxaнbl, предки, пренты, пупки, родаки, родачки, родоки, родники, родичи, родяки, рожа-

15 Григорьев Е. Культура - орудие сильнейшего // Политическая экспертная сеть «Кремль.ORG». URL: https://refdb.ru/look/1851518-p7.html (дата обращения 29.08.2016). 
ль, ханы, черепа, шнурки, шнуры и др.), в том числе учителям (классуха, клаша, козлик, преп, препод, препода, преподша, препак, тыча, училка, чира, чирик, физрук и др.), сверстникам (братуха, жеребеи, кадр, коза, конь, кобыла, корова, куриия, лось, лоб, лопух, лох, лошара, лохушка, лоходром, лохундра, лошадь, лузер, маруха, мотыга, муха, носорог, овца, тёлка, чмара, чмырь, чувак, чувиха, чухан, чушкан, чушпан, чмо, чмошник чмошница, чмырина, швабра, шмара и др.) [Бахтина, 2011].

Как показывают приведенные примеры, одной из деструктивных тенденций в речевой культуре современной русской молодежи выступает «языковая агрессия», которая выражается в негативном и критическом отношении молодежи к окружающим людям. Подобная форма речевого поведения граничит с оскорблением, причинением морального вреда другим и может привести к конфликтной ситуации.

С распадом СССР была снята цензура, в связи с чем язык современных средств массовой информации характеризуется широким распространением сквернословия, вульгаризацией, жаргонизацией. В настоящее время российские СМИ, во многом ангажированные властью, слабо выполняют свою культурно-образовательную функцию, чаще оказывают отрицательное влияние на современного человека, особенно на молодежь.

В китайском обществе наблюдаются во многом аналогичные явления. Несмотря на то, что в Китае использование жаргонизмов в эфире государственного центрального телевидения запрещено, в передачах, транслируемых провинциальными телекомпаниями (телешоу, молодежные сериалы, ток-шоу и музыкальные программы), жаргонные слова можно услышать часто. Показательны названия отдельных программ, ориентированных на молодежную аудиторию. Например, на телеканале провинции Цзэ Цзян уже долгое время существует и пользуется популярностью у молодежи телешоу «天天向上» («Каждый день стремись к лучшему»), 《快乐大本营》 (《Лагерь веселья»), 《我是歌手》 (《Я певец》), 《百变大咖秀》 (《Шоу пародий: один в один»), 《爸爸去哪儿» («Куда пропал папа?»), 《我们约会吧》 («Давайте назначим романтическое свиданье»), 《奔跑吧兄弟 («Беги, братан!») и пр.

В связи с осуществляемой правительством Китая с 90-х гг. прошлого века политикой реформ и расширения связей с внешним миром наблюдаются коренные изменения в жизни китайского народа: система традиционной культуры все более расшатывается, в обществе формируются новые понятия, ценности, новые общественные группы и субкультуры. Тенденция к тотальной жаргонизации, наблюдающаяся в современном китайском языке, является причиной серьезной обеспокоенности лингвистов, социологов, писателей, журналистов, общественных деятелей. Недавно под патронажем администрации Управления интернет-безопасности и информатизации КНР состоялся симпозиум «Очистка языка в интернете», в котором приняли участие ученые, писатели, переводчики ${ }^{16}$. Филологи рекомендовали правительству принять меры для сохранения чистоты родного языка, особенно - содействовать ограничению распространения жаргонных слов и выражений, имеющих вульгарный характер. В целом ученые высказали идею разумного, коммуникативно оправданного и целесообразного использования в речи носителей внелитературных единиц.

Таким образом, как особая социальная группа, молодежь часто находится в фокусе исследований философов, социологов, психологов и филологов, поскольку представляет индикатор состояния дел в обществе и в целом определяет тенден-

16 在网络词语大爆炸时代, 请《敬惜字纸. URL: http://news.ifeng.com/a/20150614/ 43972204_0.shtml (дата обращения 09.09.2016). 
цию и потенциал его развития. Российское и китайское общества за последние двадцать лет прошли путь коренных преобразований. Неизбежная в условиях социальных потрясений переоценка ценностей нашла отражение в первую очередь в сознании молодежи и эксплицируется представителями последней в разных сферах повседневной вербальной коммуникации. Молодежный жаргон представляет собой срез национального языка в аспекте репрезентации одной из определяющих специфику его функционирования субкультуры. Являясь, с одной стороны, средством выражения национального менталитета, жаргонизмы как лингвокультурная единица выступают, с другой стороны, объектом пристального внимания ученых - лингвистов и методистов.

\title{
Список литературы
}

Бахтина М. Б. Эмотивно-оценочная картина мира современной молодежи (на материале жаргонной лексики конца XX-XXI веков): Дис. ... канд. филол. наук. Новосибирск, 2011. 358 с.

Ван Синхуа, Курьянович A. В. Жаргонизмы в речи китайской молодежи: опыт лингвокультурологического описания // Вестн. Том. гос. пед. ун-та. 2016а. № 3 (168). С. 9-14.

Ван Синхуа, Курьянович А. В. Особенности пополнения лексического состава китайского молодежного жаргона // Диалог культур - диалог о мире и во имя мира: Материалы VII Междунар. студ. науч.-практ. конф., 20-21 апр. 2016 г. Комсомольск-на-Амуре: Изд-во Амур. гуманитарно-пед. гос. ун-та. 2016б. № 1. C. 9-16.

Ван Синхуа, Курьянович А. В., Дубина Л. В. Способ «полного погружения» в речевую среду носителей как методологическая база освоения русского языка иностранцем (на материале единиц русского жаргона) // Вестн. Том. гос. пед. ун-та. 2015. № 9(162). С. 69-75.

Дин Синь. Новый русско-китайский словарь сленга. Шанхай: Шанхайское изд-во переводной лит., 2008. 916 с.

Мудрик A. В. Социализация человека: Учеб. пособие для вузов. М.: Академия, 2004. 304 c.

Сюй Юпин. Новейший русско-китайский словарь популярных слов. Ухань: Чун Вэнь, 2006. 399 с.

Химик В. В. Язык современной молодежи // Современная русская речь: состояние и функционирование: Сб. аналитических материалов. СПб.: Изд-во С.-Петерб. гос. ун-та, 2004. С. 7-66.

Целепидис Н. В. Взаимодействие народов и культур и проблема межкультурной коммуникации молодежи // Вестн. славянской культуры. 2009. Т. 13, № 3. C. 30-34.

\author{
Wang Xinghua \\ Tomsk State Pedagogical University, Tomsk, Russian Federation \\ paveltgpu@yandex.ru \\ Russian and Chinese youth jargon \\ as manifestations of national linguistic culture and scientific objects of study \\ Recently, Russian and Chinese linguists have focused their attention on the study of youth \\ jargon units and their place and intensity of dissemination in modern Russian and Chinese speech. \\ A large number of Chinese linguistic studies deal with Russian youth jargon and unit content, \\ including, among others, the works of comparative nature, as well as dictionaries and handbooks
}


of Russian youth slang published in China. Most researchers define jargon as a special and significant phenomenon in the language which is dynamically developing. The speech of the youth acts as a symbol of the youth culture and is a powerful factor influencing the development of the language. The paper considers the functional and pragmatic features of jargon appearing in the speech of Russian and Chinese young people in a comparative aspect, taking into account the role of extralinguistic factors. The author systematises information on the stages of studying Russian youth jargon by Chinese linguists. The units of youth jargon are determined primarily as linguocultural, mediating intra- and intercultural communication. It is concluded that the similarities between Chinese and Russian jargon are due to the orientation of the cultures of both countries to the Western model. It is noted that especially during the last decade, many new lexical units have emerged in the Chinese language, denoting the realities of modern China and reflecting significant changes in all spheres of human activity. Jargon is among these units. Youth jargon represents a special subculture - a youth subculture that has its system of values, norms of behaviour and, of course, a kind of sublanguage. The possibility of using Russian youth jargon words and expressions in the practice of teaching the Russian language as a foreign to the Chinese student's language is also substantiated. The author believes that the units of Russian youth jargon if in compliance with etiquette and communicative norms can be an integral part of the didactic basis for the development of RFL in China. It is effective and expedient to use such words and expressions in courses on lexicology, colloquial speech, in studying the culture, the history of Russia and its regions.

Keywords: jargon, youth slang, jargon, linguoculture, intercultural communication.

DOI $10.17223 / 18137083 / 60 / 21$

\section{References}

Bakhtina M. B. Emotivno-otsenochnaya kartina mira sovremennoy molodezhi (na materiale zhargonnoy leksiki kontsa $X X-X X I$ vekov) [Emotion-evaluation picture of the world of modern youth (on the material of slang vocabulary of the end of the 20-21st centuries)]. Cand. philol. sci. diss. Novosibirsk, 2011, 358 p.

Wang Xinghua, Kur'yanovich A. V. Zhargonizmy v rechi kitayskoy molodezhi: opyt lingvokul'turologicheskogo opisaniya [Jargonism in the speech of Chinese youth: the experience of linguocultural description]. Tomsk State Pedagogical University Bulletin. 2016, no. 3(168), pp. 9-14.

Wang Xinghua, Kur'yanovich A. V. Osobennosti popolneniya leksicheskogo sostava kitayskogo molodezhnogo zhargona [Features of the replenishment of the lexical composition of Chinese youth jargon]. In: Dialog kul'tur - dialog o mire $i$ vo imya mira: materialy VII Mezhdunarodnoy studencheskoy nauchno-prakticheskoy konferentsii (20-21 aprelya 2016 g.). [Dialogue of cultures - dialogue on peace and for peace: materials of the VII Intern. student scientific and practical conf. (April 20-21, 2016)]. Komsomol'sk-na-Amure. Amur State Univ. of Humanities and Pedagogy publ., 2016, no 1, pp. 9-16.

Wang Xinghua, Kur'yanovich A. V., Dubina L. V. Sposob “polnogo pogruzheniya” v rechevuyu sredu nositeley kak metodologicheskaya baza osvoeniya russkogo yazyka inostrantsem (na materiale edinits russkogo zhargona) [The method of "full immersion" in the speech medium of carriers as a methodological basis for mastering the Russian language by a foreigner (on the basis of units of Russian jargon)]. Tomsk State Pedagogical University Bulletin. 2015, no. 9 (162), pp. 69-75.

Din Sin'. Novyy russko-kitayskiy slovar' slenga [New Russian-Chinese slang dictionary]. Shankhay, izd. perevodnoy lit., 2008, 916 p.

Mudrik A. V. Sotsializatsiya cheloveka: Ucheb. posob. dlya stud. vyssh. ucheb. Zavedeniy [Socialization of man: A manual for students of higher educational institutions.]. Moscow, Akademiya, 2004, 304 p.

Syuy Yupin. Noveyshiy russko-kitayskiy slovar' populyarnykh slov [The newest RussianChinese dictionary of popular words]. Ukhan', Chun Ven', 2006, 399 p.

Khimik V. V. Yazyk sovremennoy molodezhi. Sovremennaya russkaya rech': sostoyanie i funktsionirovanie: Sb. analiticheskikh materialov [Language of modern youth. Modern Russian speech: state and functioning: Sat. Analytical materials]. St. Petersburg, SPbU Publ., 2004, pp. 7-66.

Tselepidis N. V. Vzaimodeystvie narodov i kul'tur i problema mezhkul'turnoy kommunikatsii molodezhi [Interaction between peoples and cultures and the problem of intercultural communication of youth]. Bulletin of Slavic Cultures. 2009, vol. 13, no 3, pp. 30-34. 